\title{
ARTICLE \\ Deficient endocannabinoid signaling in the central amygdala contributes to alcohol dependence-related anxiety-like behavior and excessive alcohol intake
}

\author{
Antonia Serrano ${ }^{1,2}$, Francisco J. Pavon (D) ${ }^{1,2}$, Matthew W. Buczynski ${ }^{1}$, Joel Schlosburg ${ }^{3}$, Luis A. Natividad ${ }^{1}$, Ilham Y. Polis ${ }^{1}$, \\ David G. Stouffer ${ }^{1}$, Eric P. Zorrilla ${ }^{1}$, Marisa Roberto ${ }^{1}$, Benjamin F. Cravatt ${ }^{4}$, Rémi Martin-Fardon (iD), Fernando Rodriguez de Fonseca ${ }^{2}$ and \\ Loren H. Parsons ${ }^{1}$
}

\begin{abstract}
Negative emotional states that are associated with excessive alcohol intake, particularly anxiety-like states, have been linked to opponent processes in the central nucleus of the amygdala (CeA), affecting stress-related transmitters and monoamines. This study extends these observations to include endocannabinoid signaling in alcohol-dependent animals. Rats and mice were exposed to chronic intermittent alcohol with vapor inhalation or liquid diet to induce dependence. In vivo microdialysis was used to estimate interstitial concentrations of endocannabinoids [ $\mathrm{N}$-arachidonoylethanolamine (anandamide; $\mathrm{AEA}$ ) and 2-arachidonoylglycerol (2-AG)] and amino acids (glutamate and GABA) in rat CeA. Additionally, we evaluated the inhibition of endocannabinoids clearance enzymes [monoacylglycerol lipase (MAGL) and fatty acid amide hydrolase] on anxiety-like behavior and alcohol consumption in alcohol-dependent rats and mice. Results revealed that alcohol dependence produced decreases in baseline 2-AG dialysate levels and increases in baseline levels of glutamate and GABA. Acute alcohol abstinence induced an enhancement of these dependenceinduced effects and the levels of 2-AG and GABA were restored upon alcohol re-exposure. Additional studies showed that the increased CeA 2-AG levels induced by restraint stress and alcohol self-administration were blunted in alcohol-dependent rats. Pharmacological studies in rats and mice showed that anxiety-like behavior and alcohol consumption were increased in alcoholdependent animals, and these behavioral effects were attenuated mainly by MAGL inhibitors [MJN110 (10 and $20 \mathrm{mg} / \mathrm{kg})$ in rats and JZL184 (1 and $3 \mathrm{mg} / \mathrm{kg}$ ) in mice]. The present results suggest a key role for endocannabinoid signaling in motivational neuroadaptations during alcohol dependence, in which a deficiency in CeA 2-AG signaling in alcohol-dependent animals is linked to stress and excessive alcohol consumption.
\end{abstract}

Neuropsychopharmacology (2018) 43:1840-1850; https://doi.org/10.1038/s41386-018-0055-3

\section{INTRODUCTION}

Alcohol is one of the most widely used psychoactive drugs worldwide. Initial alcohol use is motivated by its hedonic and anxiolytic effects, although long-term heavy alcohol consumption progressively blunts reward system function, resulting in escalation of the frequency and amount of alcohol consumption. This situation often results in a dependent state that is characterized by enhanced sensitivity to stress and the emergence of negative emotional states during abstinence (e.g., anxiety, depression, and dysphoria) [1]. These negative emotional states derive from a greater influence of stress signaling systems, such as corticotropin-releasing factor (CRF), dynorphin, and norepinephrine, and concurrent dysregulation of mechanisms that normally constrain stress responses in the extended amygdala of the brain, such as neuropeptide $Y$ (NPY) [2-4] and nociceptin [5-9]. These symptoms are remarkably persistent during prolonged alcohol abstinence and can be alleviated by renewed alcohol consumption, suggesting that negative reinforcement mechanisms drive compulsive and excessive alcohol use in alcohol-dependent individuals [6].

The endogenous cannabinoid system (ECS) is a lipid transmitter-based system that provides integral regulation of the stress response [10], probably through actions as a retrograde messenger at both glutamate and $\gamma$-aminobutyric acid (GABA) synapses that are located along stress circuits in the brain. Stress exposure alters endocannabinoid levels in the brain in both humans and rodents [11-13]. The enhancement of endocannabinoid tone by the administration of endocannabinoid clearance inhibitors reverses stress-induced anxiety in the light-dark box and the novelty-induced hypophagia test and attenuates the stress-induced activation of corticolimbic and hypothalamic-pituitary-adrenal (HPA) axis circuits [14-16]. In contrast, the pharmacological or genetic impairment of endocannabinoid signaling increased anxiety-like behavior and heightened sensitivity to stress-induced activation of the HPA axis and amygdala [10, 17-19]. Notably, bidirectional effects of stress on

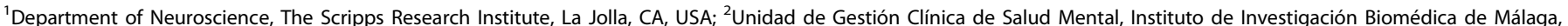

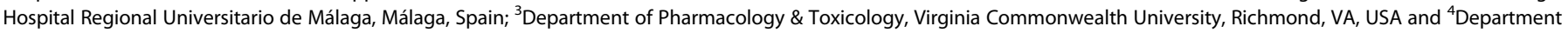
of Chemical Physiology, Skaggs Institute for Chemical Biology, The Scripps Research Institute, La Jolla, CA, USA

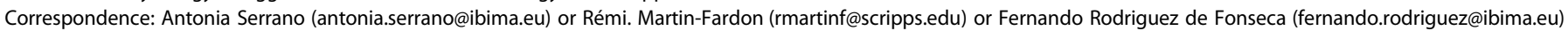
Deceased: Loren H. Parsons.

Received: 9 November 2017 Revised: 22 March 2018 Accepted: 22 March 2018

Published online: 5 April 2018 
brain levels of the endocannabinoids anandamide (AEA) and 2-arachidonoylglycerol (2-AG) have been consistently reported, with rapid but transient reductions of brain AEA levels and somewhat delayed but more sustained elevations of brain 2-AG levels [10]. Consistent with these preclinical observations, human studies demonstrated that (i) lower circulating AEA correlate with greater anxiety [11, 20,21], (ii) deficient stress-induced increases in circulating 2-AG levels are associated with excessive HPA axis activation [22], and (iii) impairments in ECS function confer vulnerability to stress-related psychiatric conditions, such as anxiety disorders, depression, and posttraumatic stress disorder $[23,24]$.

A growing body of evidence indicates that alcohol exposure dysregulates endocannabinoid signaling. Chronic alcohol exposure in rodents was shown to alter brain endocannabinoid-related gene expression in a manner that is sensitive to the intermittent nature of alcohol exposure and the post-alcohol abstinence period, although other factors such as sex differences have been reported to contribute to these alterations [25-27]. Chronic alcohol exposure also downregulates brain cannabinoid $\mathrm{CB}_{1}$ receptor expression and function. Post-mortem studies of alcohol-dependent humans reported disruptions of $\mathrm{CB}_{1}$ receptor expression in the ventral striatum and cortical regions [28], and in vivo imaging studies reported lower $\mathrm{CB}_{1}$ receptor availability in heavy drinking alcoholics that persisted for at least 1 month of abstinence $[29,30]$.

Considering the prominent role of brain endocannabinoid signaling in the regulation of stress responses and evidence that aberrant stress signaling contributes to excessive alcohol consumption and negative affective states in alcohol dependence, we tested the hypothesis that chronic intermittent alcohol exposure alters interstitial endocannabinoid levels and processing in the central nucleus of the amygdala (CeA). The $\mathrm{CeA}$ plays a critical role in the etiology of aberrant stress reactivity, anxiety-like behavior, and excessive alcohol consumption that is associated with alcohol dependence $[5,6]$. In the $\mathrm{CeA}$, the transition from initial alcohol exposure/self-administration to alcohol dependence is associated with negative emotional states and hypothesized to be mediated by allostatic opponent processes, in which the progressive recruitment of pro-stress neuromodulators (e.g., CRF) accompanies the decline of anti-stress signals, such as NPY. Early research suggested that this allostatic shift might critically involve endogenous cannabinoid signaling. We previously observed a lower $C_{1}$ receptor influence on pro-stress $\mathrm{CeA}$ signaling following chronic alcohol exposure [31]. To fully test this hypothesis, we analyzed the functional integrity and influence of endocannabinoid signaling on greater anxiety-like behavior and alcohol consumption in alcohol-dependent rats and mice using both endocannabinoid microdialysis and the pharmacological manipulation of enzymatic mechanisms for endocannabinoid clearance (fatty acid amide hydrolase (FAAH) and monoacylglycerol lipase (MAGL) inhibitors).

\section{MATERIALS AND METHODS}

Animals

We used male Wistar rats (225-250 g; Charles River Laboratories, Wilmington, MA, USA) and male C57BI/6J mice (20-30 g; The Scripps Research Institute, La Jolla, CA, USA). Rats were housed two per cage and mice were housed five per cage on a 12-h light/dark cycle (lights off at 10 a.m.). The animals had ad libitum access to food and water throughout the studies, except during exposure to an alcoholcontaining liquid diet. All of the procedures were conducted in strict adherence to Institutional Animal Care and Use Committee of The Scripps Research Institute and the National Institutes of Health Guide for the Care and Use of Laboratory Animals.

\section{Drugs}

The selective MAGL inhibitors 2,5-dioxopyrrolidin-1-yl-4-(bis[4chlorophenyl]methyl)piperazine-1-carboxylate (MJN110) and 4-nitrophenyl-4-(dibenzo[ $d][1,3]$ dioxol-5-yl[hydroxy]methyl)piperidine-1-carboxylate (JZL184) and selective FAAH inhibitor $\mathrm{N}$-(pyridin-3-yl)-4(3-[5-(trifluoromethyl)pyridin-2-yloxy]benzyl)piperdine-1-carboxamide (PF-3845) were synthesized as previously described [32-34]. All of the drugs were dissolved in vehicle (ethanol:emulphor:saline, 1:1:18) and administered intraperitoneally (i.p.). Rats were injected with vehicle, MJN110 (10 and $20 \mathrm{mg} / \mathrm{kg}$ ), or PF-3845 (3 and $10 \mathrm{mg} / \mathrm{kg}$ ) in a volume of $1 \mathrm{ml} / \mathrm{kg}$ of body weight. Mice were injected with vehicle, JZL184 (1 and 3 $\mathrm{mg} / \mathrm{kg}$ ), or PF-3845 (3 and $10 \mathrm{mg} / \mathrm{kg}$ ) in a volume of $10 \mathrm{ml} / \mathrm{kg}$ of body weight.

Chronic intermittent alcohol exposure

Groups of animals with a history of alcohol dependence were referred as "alcohol group", while groups of animals without a history of alcohol dependence were referred as "control group".

Alcohol liquid diet. Regular chow diet was removed and replaced with a liquid diet that consisted of chocolate-flavored Boost liquid nutritional supplement fortified with vitamins and minerals (Nestle HealthCare Nutrition, Florham Park, NJ, USA). The rats were separated into two groups. The alcohol group received a diet that contained $10 \%(\mathrm{w} / \mathrm{v})$ alcohol, and the control group received an alcohol-free diet supplemented with sucrose to equalize the caloric intake in both groups. The diet was available $24 \mathrm{~h}$ per day for 5 days per week. On weekends, the animals were given ad libitum access to chow and water. This schedule was maintained for 3 weeks.

Alcohol vapor inhalation. We used the standard alcohol inhalation method of The Scripps Research Institute Alcohol Research Center [35]. Rats were housed 2-4 per cage with free access to food and water and were placed into either alcohol vapor chambers (14-h vapor ON/10-h vapor OFF per day) or into air-only chambers (sham naive controls) for 3 weeks. In the studies that administered MAGL and FAAH inhibitors, alcohol dependence was induced in rats and mice by three cycles of intermittent alcohol vapor inhalation on alternate weeks for 5 weeks.

Blood alcohol concentration measurements

Once per week, we determined blood alcohol concentration (BAC) of the animals from tail-blood samples using the alcohol oxidase method (Analox Instruments, Lunenburg, MA, USA).

\section{Alcohol consumption procedures}

Operant alcohol self-administration procedure. Operant alcohol self-administration testing was conducted in standard operant conditioning chambers using a procedure previously described [36], which is equivalent to the sucrose-fading procedure. In brief, rats were trained to orally self-administer $10 \%$ alcohol $(\mathrm{w} / \mathrm{v})$ or water on a fixed ratio (FR1; one active lever press required for $0.1 \mathrm{ml}$ of the solution). Animals learned to work for alcohol prior to induction of dependence. Thus, upon the stabilization of operant responding, the rats were divided into two groups and exposed for 3 weeks to air (non-dependent) or intermittent alcohol vapors (dependent). For details, see Supplementary Information.

Two-bottle choice drinking paradigm. After 4 days of water consumption from two bottles, mice were given access to one bottle of $10 \%(\mathrm{v} / \mathrm{v})$ alcohol and one bottle of water until a stable baseline was reached. The bottle positions were changed every day to avoid position preferences. Alcohol intake $(\mathrm{g} / \mathrm{kg})$ was calculated for each animal. Evaporation/spillage estimates were calculated using an empty cage with two bottles, which contained water and alcohol solution. 
Acute restraint stress exposure

During the microdialysis procedure, a 30-min immobilization stress procedure was used. Each animal was restrained by immobilization for 30 min using a previously published procedure [37].

In vivo microdialysis studies

Surgery. Rats were stereotaxically implanted with a microdialysis guide cannula (21 gauge, Plastics One, Roanoke, VA, USA) aimed at the CeA (relative to bregma: anterior/posterior, $-2.3 \mathrm{~mm}$; $\mathrm{medial} /$ lateral, $+4.0 \mathrm{~mm}$; dorsal/ventral, $-6.4 \mathrm{~mm}$ from dura) [38].

In vivo microdialysis procedure. Microdialysis and quantification of endocannabinoids and amino acids were performed in separate experiments.

The day before the microdialysis session, a microdialysis probe was inserted and secured to the implanted guide cannula. The microdialysis probe was perfused with artificial cerebrospinal fluid (aCSF; $145 \mathrm{mM} \mathrm{NaCl}, 2.8 \mathrm{mM} \mathrm{KCl}, 1.2 \mathrm{mM} \mathrm{CaCl}, 1.2 \mathrm{mM} \mathrm{MgCl}$, $0.25 \mathrm{mM}$ ascorbic acid, and $5.4 \mathrm{mM}$ D-glucose [pH 7.2-7.4]) overnight at $0.2 \mu \mathrm{l} / \mathrm{min}$. The following day the aCSF perfusate was replaced by aCSF that contained $30 \%(\mathrm{w} / \mathrm{v})$ hydroxypropyl- $\beta$ cyclodextrin to increase the recovery of endocannabinoids [39]. This step was only necessary during endocannabinoid microdialysis. The perfusion flow rate was then increased to $0.6 \mu \mathrm{l} / \mathrm{min}$ for $120 \mathrm{~min}$ to reach interstitial equilibrium before sample collection. The dialysate samples were subsequently collected every 10 min throughout each experiment, frozen on dry ice, and stored at $-80^{\circ} \mathrm{C}$.

Prior to neurochemical determinations, histological verifications were conducted to include all cases that the active dialysis membrane was properly located within the CeA.

Neurochemical determinations. The endocannabinoid and amino acid dialysate content was determined using liquid chromatography coupled with mass spectrometry (LC-MS) and capillary electrophoresis with laser-induced fluorescence detection (CE-LIF), respectively (for details, see Supplementary Information). For clarity of presentation of the neurochemical data, the quantity of endocannabinoids and amino acids in a volume of collection of 6 $\mu \mathrm{l}$ was expressed in units of concentration (nM). Because a conventional microdialysis procedure provides information regarding relative changes in transmitter efflux and does not reflect the actual extracellular concentration [40], the data were reported as dialysate levels in the results and discussion.

\section{Elevated plus maze}

Rats and mice were tested in the elevated plus maze (EPM) 7 days after air/alcohol vapor offset. The dimensions of the EPM apparatus were different for rats and mice (for details, see Supplementary Information). At the beginning of the test, each animal was placed in the center of the maze, facing an open arm, and was allowed to freely explore the maze for $5 \mathrm{~min}$. The percent time spent on the open arms (time spent on open arms/total time $x$ 100) was calculated.

\section{RNA isolation and RT-qPCR analysis}

Rats were anesthetized by isoflurane inhalation and killed $12 \mathrm{~h}$ after air/alcohol vapor offset. We sectioned brains coronally $(2 \mathrm{~mm}$ slices) in a rat brain matrix, and punches that contained the $\mathrm{CeA}$ were obtained using a 14-gauge needle, guided by a stereotaxic atlas [38], and stored at $-80^{\circ} \mathrm{C}$ until processing. Total RNA was extracted using Trizol reagent (Gibco BRL Life Technologies, Baltimore, MD, USA), and the concentrations were quantified using a spectrophotometer to ensure ratios of absorbance at 260-280 nm of 1.8-2.0. Reverse transcription was performed using the SuperScript First-Strand Synthesis System for RT-PCR (Invitrogen) in the presence of Oligo (dT)12-18 according to the manufacturer's instructions. RT-qPCR was performed using an ABI PRISMR 7300 Real-Time PCR System (Applied Biosystems, Foster City, CA, USA) and the FAM dye label format for the TaqMan Gene Expression Assays (Applied Biosystems). The absolute values from each sample were normalized to the housekeeping gene cyclophilin A (Сyp). Relative quantification was calculated using the $\Delta \Delta \mathrm{Ct}$ method and normalized to the control group. Primers for RT-qPCR were obtained based on the Applied Biosystems genome database of rat mRNA references (http://bioinfo. appliedbiosystems.com/genome-database/gene-expression.html; accessed 1 August 2017; Supplementary Table S1).

Statistical analysis

Microdialysis study. Repeated-measures analysis of variance (ANOVA) was first conducted to examine significant differences between the alcohol and control groups across the baseline dialysate levels of 2-AG, AEA, GABA, and glutamate in the microdialysis studies. For each group, the mean baseline level was calculated as the average of all dialysate samples that were collected over a $60-\mathrm{min}$ period at 10 -min intervals (6 samples/ animal). Subsequent analyses were conducted on dialysate data using two-way repeated-measures ANOVA, with alcohol history (alcohol and control) as the between-subjects factor and sampling time (10-min intervals) as the within-subjects factor, to determine the impact of 30-min exposure to restraint stress or alcohol selfadministration on 2-AG and AEA interstitial levels and the impact of 12-h abstinence on 2-AG, AEA, GABA, and glutamate. One-way repeated-measures ANOVA was conducted to examine dialysate levels over time in each group (alcohol and control). The HolmSidak test was used for multiple comparisons.

Pharmacological studies on anxiety-like behavior and alcohol consumption. Alcohol intake and the behavioral variables were analyzed in rats and mice using a two-way ANOVA and planned pairwise $t$-tests (Bonferroni correction) based on microdialysis data. "Alcohol history" (alcohol and control) and "drug dose" with MJN110, JZL184, and PF-3845 were used as factors in the ANOVA.

Gene expression. Relative mRNA expression of endocannabinoid enzymes and receptors was analyzed using unpaired Student's $t$ test between control and alcohol animals.

Test statistic values and degrees of freedom are indicated in the results where appropriate. Values of $p<0.05$ were considered statistically significant. All of the statistical analyses were performed using Prism software (GraphPad, San Diego, CA, USA).

\section{RESULTS}

Effects of chronic alcohol exposure and abstinence on amino acids and endocannabinoids in the $\mathrm{CeA}$

2-AG dialysate levels. Repeated-measures ANOVA revealed a significant main effect of alcohol history on baseline 2-AG levels $\left(F_{1,12}=5.69, p=0.034\right)$ (Fig. 1a). Baseline 2-AG levels were significantly lower in alcohol rats compared with control rats. Overall, a two-way repeated-measures ANOVA revealed significant main effects of alcohol history $\left(F_{1,12}=13.44, p=0.003\right)$ and sampling time $\left(F_{34,408}=15.21, p<0.001\right)$ on 2 -AG levels and a significant interaction $\left(F_{34,408}=8.91, p<0.001\right)$. Changes in 2-AG levels were observed in alcohol but not in control rats, indicated by the one-way repeated-measures ANOVA $\left(F_{34,204}=15.37, p<0.001\right)$. 2-AG levels decreased over the course of $12-\mathrm{h}$ alcohol abstinence compared with baseline levels, although 2-AG returned to pre-abstinence (baseline) levels following renewed alcohol intake (significant difference compared with baseline 2-AG levels [ $p<0.05]$ in alcohol rats). In contrast, $\mathrm{CeA}$ 2-AG levels were stable over the same sampling period in the control group. 

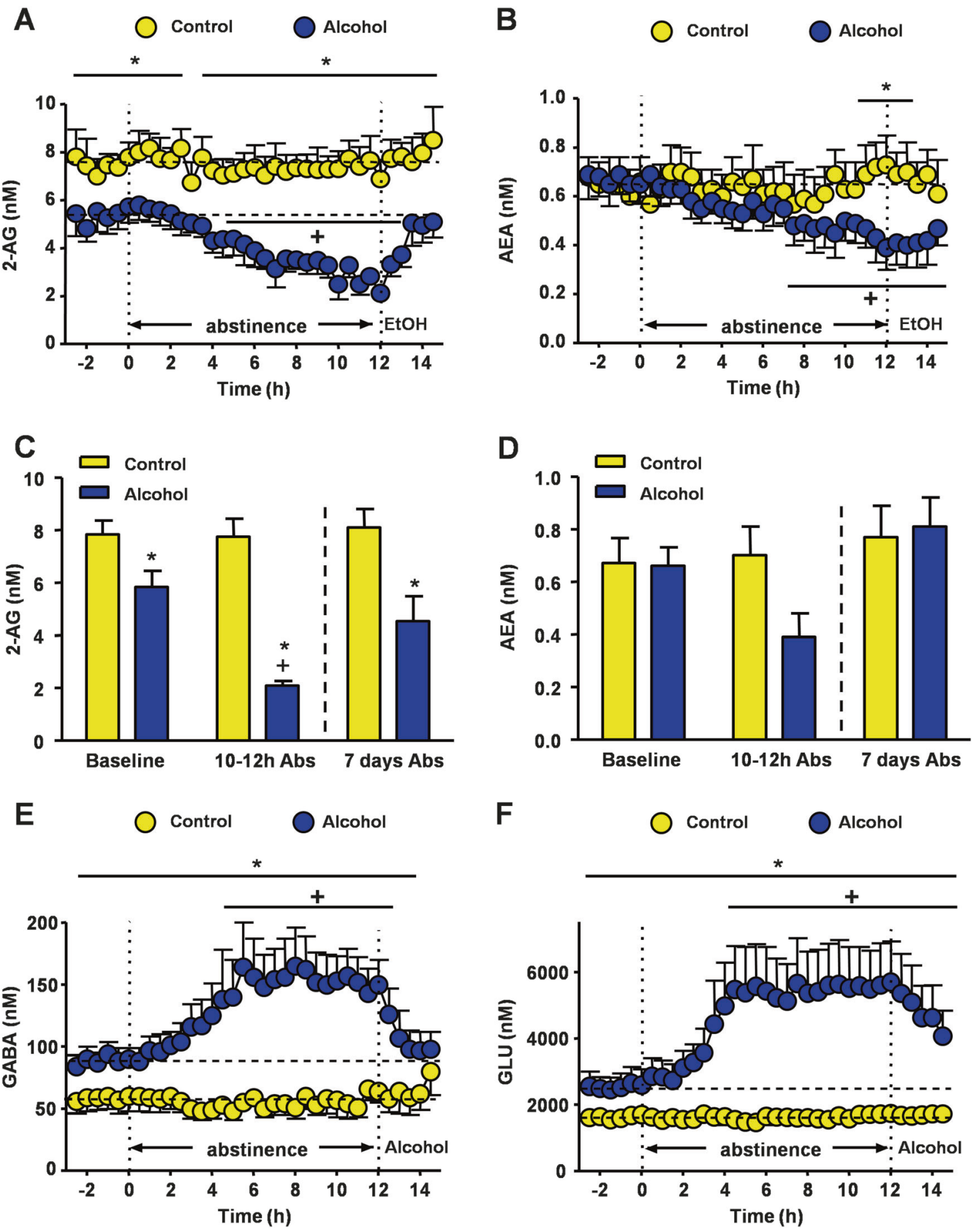

Fig. 1 Effects of chronic alcohol exposure and abstinence on endocannabinoids and amino acids in the rat CeA. Profile of CeA dialysate a 2-AG, b AEA, e GABA, and f glutamate levels in alcohol $(n=7)$ and control $(n=7)$ rats over 12-h alcohol abstinence and subsequent renewed alcohol consumption. Alcohol dependence was induced in rats by 21 days of intermittent maintenance on an alcohol-containing liquid diet (mean alcohol intake: $7.8 \pm 0.3 \mathrm{~g} / \mathrm{kg} /$ day; mean BAC: $234 \pm 70 \mathrm{mg} \%$ ). Non-dependent rats were maintained on an equicaloric alcohol-free liquid diet. On the final day of alcohol exposure, CeA microdialysis samples were collected for a 3-h period (baseline), during which alcohol rats had access to the alcohol-containing diet (alcohol consumption was approximately $5 \mathrm{~g} / \mathrm{kg}$ for $3 \mathrm{~h}$ ), and control rats had access to the familiar alcohol-free diet. Following baseline dialysate collection, the alcohol-containing diet was replaced with the control diet for $12 \mathrm{~h}$, during which sample collection continued at $30 \mathrm{~min}$ intervals. At the end of this $12-\mathrm{h}$ period of abstinence, the alcohol-containing diet was replaced, and sampling continued for an additional $2.5 \mathrm{~h}$ (alcohol consumption was approximately $4 \mathrm{~g} / \mathrm{kg}$ during this period). Effect of acute (10-12 h) and protracted (7 days) abstinence on CeA c 2-AG and d AEA dialysate levels in alcohol and control rats. The data are expressed as mean \pm SEM. ${ }^{*} p<0.05$, significant difference between alcohol and control groups; ${ }^{+} p<0.05$, significant difference relative to baseline dialysate levels 
AEA dialysate levels. There was no significant effect of alcohol history on baseline AEA levels, but the analysis of AEA levels in the microdialysis session revealed a main effect of sampling time $\left(F_{34,408}=4.65, p<0.001\right)$ and a significant interaction between factors $\left(F_{34,408}=6.36, p<0.001\right)$ (Fig. 1b). The one-way repeatedmeasures ANOVA revealed significant changes in AEA levels in alcohol rats $\left(F_{34,204}=6.48, p<0.001\right)$ because there was a progressive reduction of AEA during 12-h abstinence compared with baseline levels, which was also observed following renewed alcohol consumption (significant differences relative to baseline AEA levels $[p<0.05])$.

Next, we evaluated whether alcohol dependence-associated deficits in $\mathrm{CeA}$ endocannabinoid dialysate levels persist during protracted abstinence (7 days) using different animals for each subgroup (baseline, 10-12 h and 7 days). As shown in Fig. 1c, the two-way ANOVA revealed main effects of alcohol history $\left(F_{1,40}=\right.$ $45.24, p<0.001)$ and sampling time $\left(F_{2,40}=4.47, p=0.018\right)$ on CeA 2-AG levels and a significant interaction between factors $\left(F_{2,40}=3.72, p=0.033\right)$. The Holm-Sidak test for multiple comparisons showed that 2-AG levels were significantly lower in alcohol rats than in control rats $(p<0.05)$ at all sampling times, with a significant decrease in 2-AG levels in the 10-12 $\mathrm{h}$ of abstinence subgroup compared with the baseline subgroup in the alcohol group $(p<0.05)$. In contrast, there were no differences in $2-A G$ levels when the 7 days of abstinence subgroup was compared with the baseline subgroup.

The two-way ANOVA revealed no main effects of alcohol history and sampling time on AEA levels and no interaction between factors (Fig. 1d).

GABA dialysate levels. The repeated-measures ANOVA revealed a significant main effect of alcohol history on baseline GABA levels $\left(F_{1,12}=5.63, p=0.035\right)$ (Fig. 1e). GABA levels were significantly higher in alcohol rats than in control rats. The two-way repeatedmeasures ANOVA revealed main effects of alcohol history $\left(F_{1,12}=\right.$ $10.31, p=0.007)$ and time sampling $\left(F_{34,408}=11.94, p<0.001\right)$ and a significant interaction between factors $\left(F_{34,408}=15.85, p<0.001\right)$. The one-way repeated-measures ANOVA indicated significant changes in GABA levels during microdialysis in alcohol rats at different sampling times $\left(F_{34,204}=8.48, p<0.001\right)$. The high GABA dialysate levels in alcohol rats compared with controls further increased over the course of $12-\mathrm{h}$ abstinence, and the renewed alcohol consumption decreased dialysate GABA levels to preabstinence baseline levels (significant differences relative to baseline GABA levels $[p<0.05])$. Control rats exhibited no changes in GABA dialysate levels in the $\mathrm{CeA}$ over the course of sampling.

Glutamate dialysate levels. There was a main effect of alcohol history on baseline glutamate levels $\left(F_{1,12}=4.98, p=0.045\right)$ (Fig. 1f). Glutamate levels were significantly higher in alcohol rats compared with control rats. The analysis of glutamate levels revealed main effects of alcohol history $\left(F_{1,12}=9.54, p=0.009\right)$ and sampling time $\left(F_{34,408}=13.22, p<0.001\right)$ and a significant interaction between factors $\left(F_{34,408}=13.03, p<0.001\right)$. The one-way repeated-measures ANOVA confirmed significant changes at different sampling times in the alcohol group $\left(F_{34,204}=7.20\right.$, $p<0.001)$. The high levels of glutamate in the alcohol group compared with controls were enhanced during alcohol abstinence, and these dialysate levels then diminished after replacing the alcohol-containing diet, although not fully to pre-abstinence baseline levels (significant differences relative to baseline glutamate levels $[p<0.05]$ ). Control rats exhibited no changes in glutamate dialysate levels over the microdialysis sampling time.

Effects of chronic alcohol exposure and restraint stress on endocannabinoids in the $\mathrm{CeA}$

Repeated-measures ANOVA revealed a main effect of alcohol history on baseline 2-AG levels $\left(F_{1,16}=5.02, p=0.040\right)$ (Fig. 2a). Alcohol rats exhibited significantly lower 2-AG levels than control rats. Overall, the two-way repeated-measures ANOVA revealed a main effect of sampling time on 2-AG levels $\left(F_{17,272}=8.23, p<0.001\right)$ and a significant interaction between factors $\left(F_{17,272}=3.96, p<0.001\right)$. A 30-min period of restraint stress increased 2-AG levels that was sustained for the remaining $90 \mathrm{~min}$ in the control group, and this increase was absent in alcohol rats. Separate one-way repeatedmeasures ANOVAs for each group revealed significant differences in 2-AG dialysate levels during the microdialysis session in control rats $\left(F_{17,153}=4.21, p<0.001\right.$; significant differences relative to baseline 2-AG levels $[p<0.05])$ but not in alcohol rats.

The mean baseline AEA levels in alcohol rats did not differ when compared with control rats (Fig. 2b). The statistical analysis only revealed a main effect of sampling time $\left(F_{17,272}=1.85, p=0.022\right)$ on AEA dialysate levels for both groups with a transient decrease during the 30-min restraint.

Effects of chronic alcohol exposure and alcohol self-administration on endocannabinoids in the $\mathrm{CeA}$

There was a main effect of alcohol history on baseline 2-AG levels $\left(F_{1,16}=5.34, p=0.035\right)$ (Fig. $\left.2 c\right)$. Alcohol rats had lower baseline 2-AG levels than control rats. Overall, the two-way repeatedmeasures ANOVA revealed significant main effects of alcohol history $\left(F_{1,16}=5.55, p=0.032\right)$ and sampling time $\left(F_{17,272}=15.05\right.$, $p<0.001$ ) on 2-AG levels and a significant interaction between factors $\left(F_{17,272}=9.27, \quad p<0.001\right)$. A subsequent 30 -min selfadministration session led to a steady increase in 2-AG levels in control rats, but no alterations were observed in alcohol rats. This was confirmed by two separate one-way repeated-measures ANOVAs that revealed significant differences in 2-AG dialysate levels during the sampling time in the control group $\left(F_{17,136}=\right.$ $1.38, p<0.001$; significant differences relative to baseline $2-A G$ levels $[p<0.05])$ but not in the alcohol group.

There was no significant effect of alcohol history on baseline AEA levels (Fig. 2d) and the two-way repeated-measures ANOVA revealed no main effects or interaction between alcohol history and sampling time on AEA levels during the microdialysis session.

The number of lever presses during 30-min self-administration sessions that were performed during the microdialysis experiments is shown in Fig. 2e. The two-way ANOVA revealed main effects of alcohol history $\left(F_{1,16}=5.41, p=0.033\right)$ and alcohol selfadministration time $\left(F_{2,32}=27.11, p<0.001\right)$ on active lever presses and a significant interaction between factors $\left(F_{2,32}=\right.$ $15.49, p<0.001)$. Control rats exhibited stable self-administration throughout the entire session, whereas alcohol rats substantially increased their alcohol self-administration after the initial 10-min period. The Holm-Sidak test for multiple comparisons showed that alcohol rats self-administered signifsicantly more alcohol than controls at $30 \mathrm{~min}(p<0.05)$.

Effects of MAGL and FAAH inhibitors on anxiety-like behavior in chronic alcohol exposure

MAGL inhibition. As shown in Fig. 3a, anxiety-like behavior was assessed in alcohol and control rats treated with MJN110 or vehicle. A two-way ANOVA indicated significant main effects of alcohol history $\left(F_{1,57}=4.07, p=0.048\right)$ and drug dose $\left(F_{2,57}=3.27\right.$, $p=0.045$ ) on open arm time, but also a significant interaction effect $\left(F_{2,57}=3.69, p=0.031\right)$. Pairwise $t$-tests revealed a significant decrease in open arm time only in alcohol vehicle-treated rats compared with control rats $\left(t_{19}=2.85, p<0.05\right)$. In fact, alcohol rats treated with $20 \mathrm{mg} / \mathrm{kg}$ MJN110 showed a significant increase in open arm time relative to alcohol vehicle-treated rats $\left(t_{18}=\right.$ $3.45, p<0.01$ ) and the anxiety-like behavior was normalized to the control group.

In mice (Fig. 3b), there was a main effect of drug dose $\left(F_{2,54}=\right.$ $3.45, p=0.039)$ and a significant interaction between alcohol history and drug dose $\left(F_{2,54}=3.26, p=0.046\right)$ on anxiety-like behavior. Pairwise comparisons revealed significantly lower open 


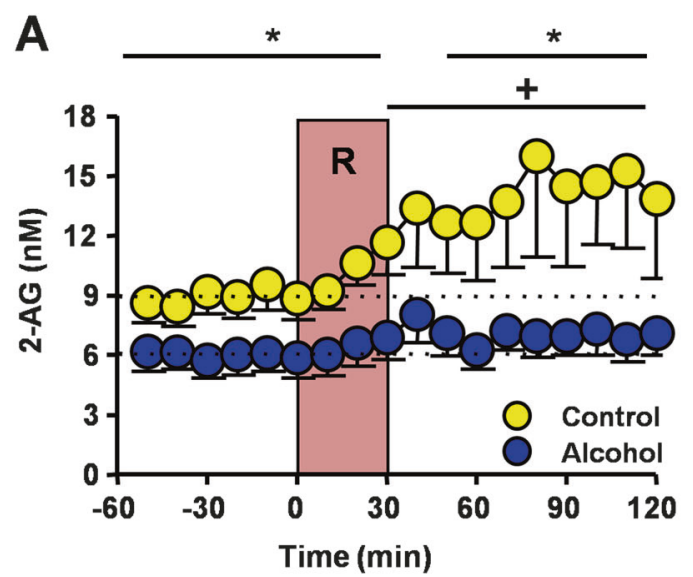

B
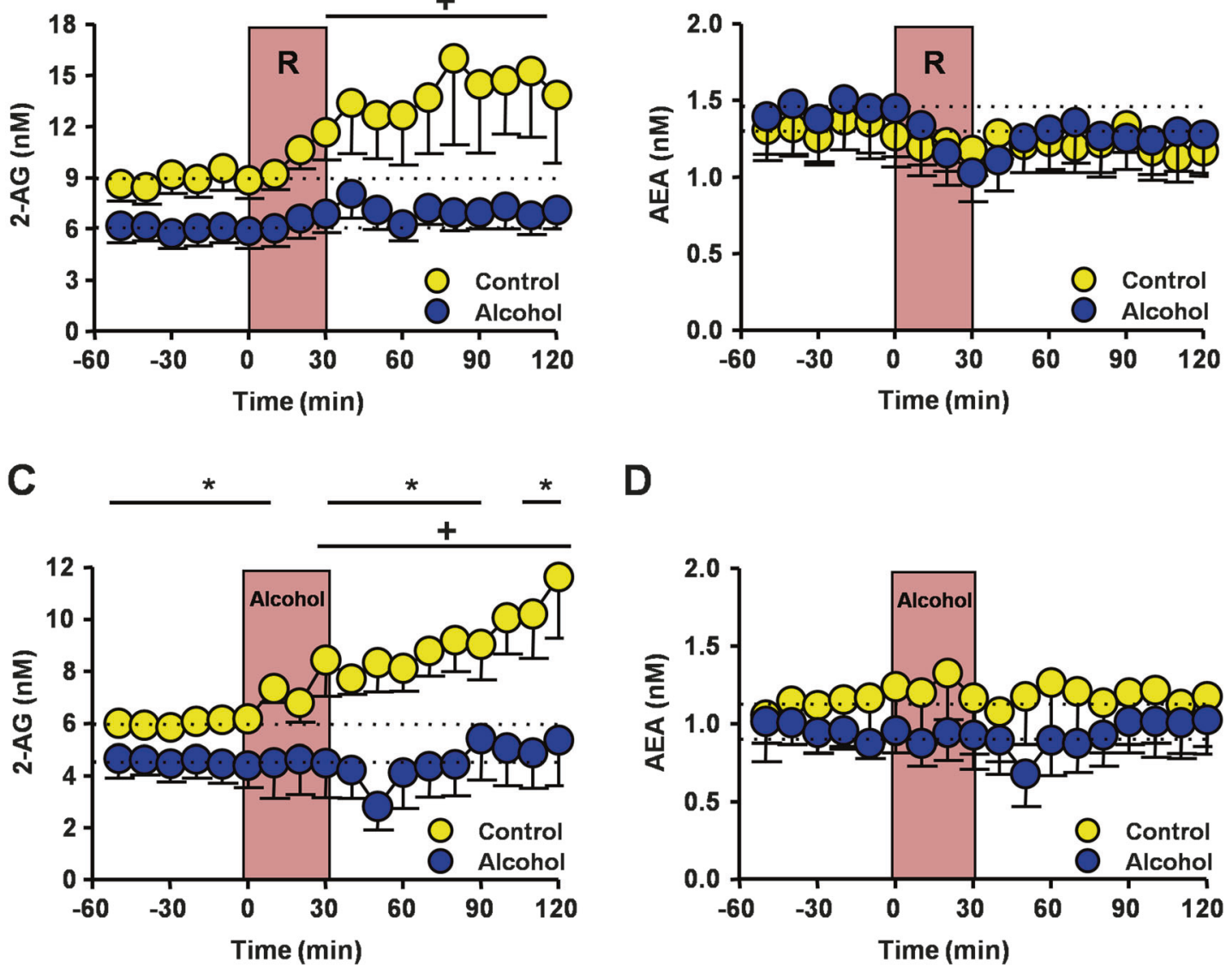

E

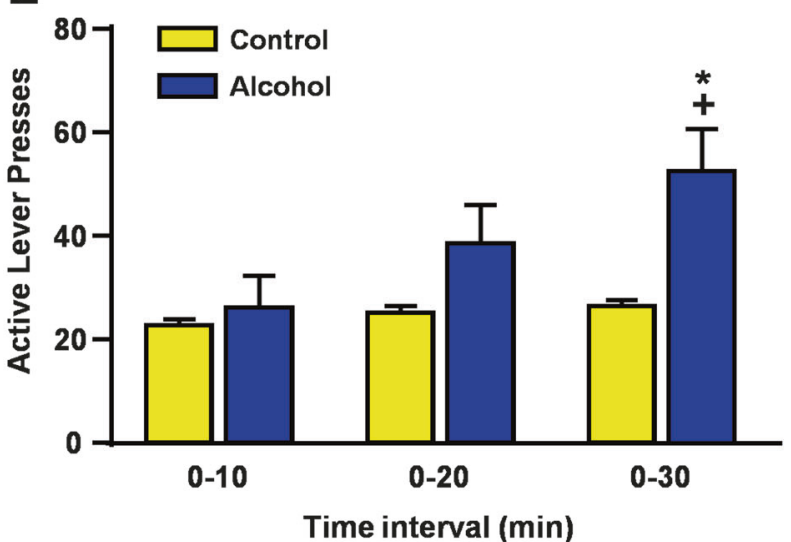

Fig. 2 Effects of restraint stress and alcohol self-administration on CeA dialysate endocannabinoid levels in alcohol-dependent and -nondependent rats. Effects of 30-min restraint stress on a 2-AG and b AEA levels in CeA microdialysates collected from alcohol $(n=8)$ and control $(n=10)$ rats. Alcohol dependence was induced by 21 days of exposure to intermittent alcohol vapor inhalation (mean BAC: $234 \pm 13$ mg\%). Following 7 days of abstinence, baseline dialysate samples were collected at 10-min intervals for 60 min, after which each animal was restrained for $30 \mathrm{~min}$. Dialysate samples were collected at 10-min intervals during restraint stress and for 90 min afterward. Effects of $30-\mathrm{min}$ alcohol self-administration session on c 2-AG and $\mathbf{d}$ AEA levels in CeA microdialysates collected from alcohol $(n=9)$ and control $(n=9)$ rats. Alcohol dependence was induced by 21 days of exposure to intermittent alcohol vapor inhalation (mean BAC: $230 \pm 9$ mg\%). Following $5 \mathrm{~h}$ of abstinence, baseline dialysate samples were collected at 10-min intervals for $60 \mathrm{~min}$, after which each animal was placed in an operant chamber and allowed to self-administered alcohol for $30 \mathrm{~min}$. Dialysate samples were collected for an additional $90 \mathrm{~min}$ after the selfadministration session. e Number of active lever presses during the self-administration session at different cumulative time intervals. The data are expressed as mean \pm SEM. ${ }^{*} p<0.05$, significant difference between alcohol and control groups; ${ }^{+} p<0.05$, significant difference relative to baseline dialysate levels 
A

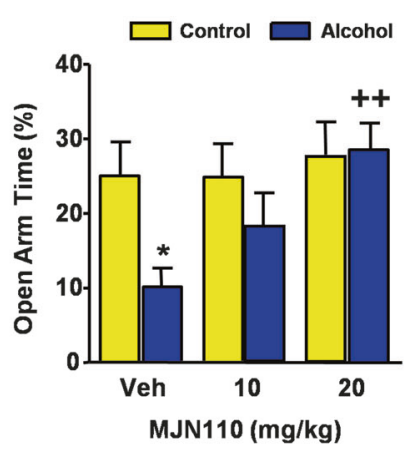

E

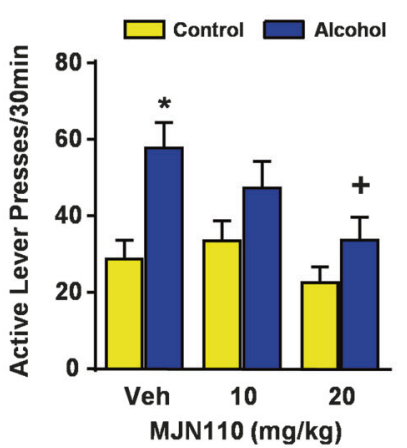

B

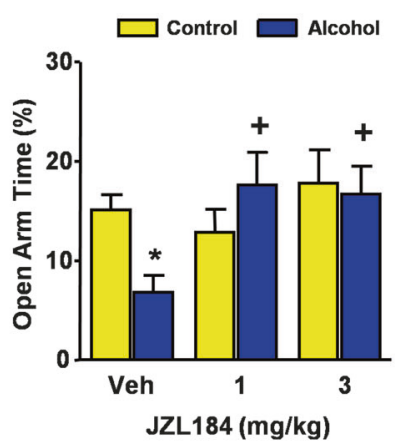

F

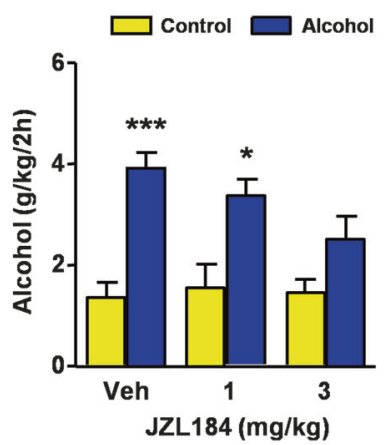

C

FAAH: rat

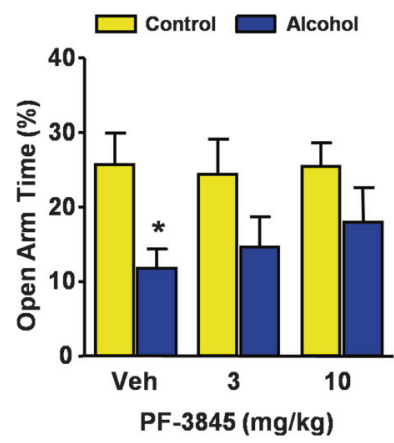

G

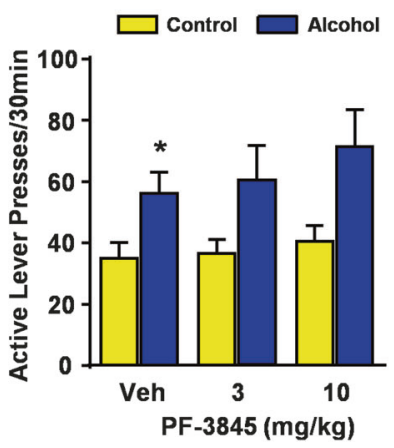

D FAAH: mouse

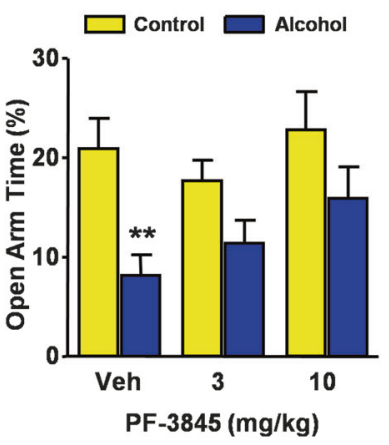

H

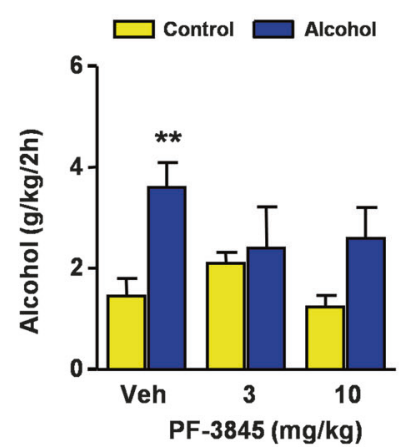

Fig. 3 Effects of MAGL and FAAH inhibitors on abstinence-related anxiety-like behavior and alcohol intake in alcohol-dependent and -nondependent rodents. Alcohol dependence was induced by three cycles of intermittent alcohol vapor inhalation on alternate weeks for 5 weeks (mean BAC: $249 \pm 12 \mathrm{mg} \%$ in rats and $277 \pm 15 \mathrm{mg} \%$ in mice). After 7 days of abstinence, anxiety-like behavior and alcohol intake were evaluated. Alcohol abstinence-related anxiety-like behavior was evaluated in alcohol and control rodents that were treated with the MAGL inhibitors a MJN110 ( $n=10-11$ rats) and b JZL184 $(n=10$ mice) or the FAAH inhibitors c PF-3845 $(n=7-8$ rats $)$ and d PF-3845 $(n=8$ mice). Open arm time was used as an inverse measure of anxiety-like behavior. Alcohol intake was determined using operant alcohol selfadministration in 30-min sessions in rats and the two-bottle choice paradigm in 2-h sessions in mice after treatment with the MAGL inhibitors e MJN1 10 ( $n=7-8$ rats) and f JZL184 ( $n=10$ mice) or the FAAH inhibitors g PF-3845 $(n=11$ rats) and h PF-3845 ( $n=10$ mice) in alcohol and control rodents. The data are expressed as mean \pm SEM. ${ }^{*} p<0.05,{ }^{* *} p<0.01$, and ${ }^{* * *} p<0.001$ denote significant differences relative to respective control animals; ${ }^{+} p<0.05$ and ${ }^{++} p<0.01$ denote significant differences relative to alcohol vehicle-treated animals

arm time in alcohol vehicle-treated mice compared with controls $\left(t_{18}=3.13, p<0.05\right)$, but not in JZL184-treated mice. Thus, alcohol mice treated with 1 and $3 \mathrm{mg} / \mathrm{kg}$ JZL184 showed a significant increase in open arm time relative to alcohol vehicle-treated mice $\left(t_{18}=2.91, p<0.05\right.$ and $t_{18}=3.02, p<0.05$, respectively), which resulted in a normalization of anxiety-like behavior.

FAAH inhibition. In rats treated with PF-3845 or vehicle (Fig. 3c), a two-way ANOVA revealed only a main effect of alcohol history $\left(F_{1,39}=10.32, \quad p=0.003\right)$ and higher anxiety behavior was observed in the alcohol group. However, $t$-tests showed significantly lower open arm time in alcohol vehicle-treated rats than in controls $\left(t_{13}=2.89, p<0.05\right)$, but not in alcohol PF-3845treated rats.

Regarding mice treated with FAAH inhibitor or vehicle (Fig. 3d), there was only a significant main effect of alcohol history $\left(F_{1,42}=\right.$ 14.09, $p<0.001$ ) and alcohol mice displayed higher anxiety behavior than controls. Similar to rats, planned $t$-tests showed that there was a significant decrease in open arm time in alcohol vehicle-treated mice $\left(t_{14}=3.49, p<0.01\right)$ but not in alcohol mice treated with 3 and $10 \mathrm{mg} / \mathrm{kg}$ PF-3845.

Effects of MAGL and FAAH inhibitors on alcohol intake in chronic alcohol exposure

MAGL inhibition. As shown in Fig. 3e, alcohol intake was assessed in alcohol and control rats that were treated with MJN110 or vehicle. Overall, a two-way ANOVA of alcohol self-administration revealed main effects of alcohol history $\left(F_{1,39}=14.24, p<0.001\right)$ and drug dose $\left(F_{2,39}=3.78, p=0.032\right)$, but more importantly a significant interaction effect between both factors $\left(F_{2,39}=3.47\right.$, $p=0.041$ ). Pairwise $t$-tests of alcohol and control rats for each drug dose revealed a significant increase in alcohol intake in vehicletreated rats $\left(t_{13}=3.42, p<0.05\right)$ but not in alcohol MJN110-treated rats. In addition, alcohol rats treated with $20 \mathrm{mg} / \mathrm{kg}$ MJN110 showed a significant decrease in alcohol consumption relative to alcohol vehicle-treated rats $\left(t_{14}=2.70, p<0.05\right)$.

In mice, the effects of JZL184 on alcohol consumption followed a similar pattern as rats that were treated with MJN110 (Fig. 3f). There were significant main effects of alcohol history $\left(F_{1,54}=\right.$ $22.98, p<0.001)$ and drug dose $\left(F_{2,54}=4.89, p=0.011\right)$ on alcohol intake but no interaction effect. Therefore, the alcohol group showed higher alcohol intake than the control group, and higher dose of JZL184 was accompanied of lower alcohol intake. However, planned pairwise comparisons revealed that the significant increase in alcohol intake was observed in mice treated with vehicle $\left(t_{18}=4.47, p<0.001\right)$ and $1 \mathrm{mg} / \mathrm{kg} \mathrm{JZL184}\left(t_{18}=2.78\right.$, $p<0.05)$ compared with the respective control subgroup, but not with $3 \mathrm{mg} / \mathrm{kg} \mathrm{JZL184.}$

FAAH inhibition. Alcohol and control rats were treated with PF3845 or vehicle (Fig. $3 \mathrm{~g}$ ). There was only a main effect of alcohol history $\left(F_{1,60}=16.42, p<0.001\right)$ and higher alcohol intake was 


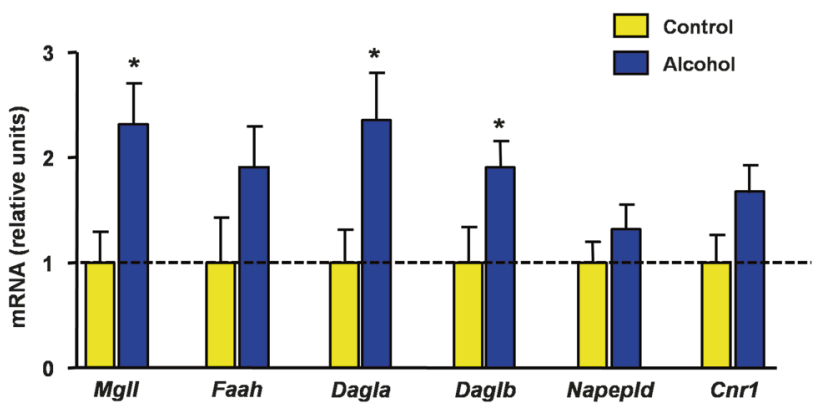

Fig. 4 Effects of chronic alcohol exposure on endocannabinoidrelated gene expression in the rat $\mathrm{CeA}$. Alcohol dependence was induced by 21 days of exposure to intermittent alcohol vapor inhalation. At $12 \mathrm{~h}$ of abstinence, the mRNA expression of genes that is associated with the ECS (Mgll, Faah, Dagla, Daglb, Napepld, and Cnr1) was examined in the CeA in alcohol $(n=11)$ and control $(n=$ 9) rats. The data are expressed as mean \pm SEM. ${ }^{*} p<0.05$, significant difference between alcohol and control groups

observed in the alcohol group. However, planned pairwise $t$-tests showed that there was a significant increase in alcohol intake in alcohol vehicle-treated rats $\left(t_{14.55}=3.07, p<0.05\right)$ but not in rats treated with 3 and $10 \mathrm{mg} / \mathrm{kg}$ PF-3845.

In mice treated with PF-3845 or vehicle (Fig. 3h), a two-way ANOVA also revealed a significant main effect of alcohol history $\left(F_{1,54}=9.84, p=0.003\right)$ on alcohol consumption. Similar to rats, the planned $t$-tests showed that there was a significant increase in alcohol intake only in alcohol vehicle-treated mice compared with controls $\left(t_{18}=3.56, p<0.01\right)$ but not in mice treated with 3 and $10 \mathrm{mg} / \mathrm{kg}$ PF-3845.

Effects of chronic alcohol exposure on endocannabinoid-related gene expression in the $\mathrm{CeA}$

As shown in Fig. 4, the alcohol group showed an overall increase in the mRNA expression of enzymes related to the endocannabinoid signaling in the CeA. However, unpaired $t$-tests between alcohol and control rats only revealed significant differences in the mRNA levels of enzymes involved in 2-AG metabolism: MAGL $\left(t_{20}=2.68, p<0.05\right)$ and diacylglycerol lipases $\left(\mathrm{DAGL}_{\mathrm{\alpha} / \beta}\right) \quad\left(t_{20}=\right.$ $2.46, p<0.05$ and $t_{20}=2.16, p<0.05$, respectively).

\section{DISCUSSION}

Alcohol dependence and abstinence are associated with greater stress reactivity and anxiety that partially result from dysregulated neural signaling in the $\mathrm{CeA}[5,6]$. These affective disruptions emerge during early abstinence, persist beyond the dissipation of somatic abstinence symptoms, and are known to be significant triggers of relapse to drinking. Based on evidence that suggests that stress-induced endocannabinoid recruitment constrains stress responsivity and reduces anxiety-like behavioral effects $[22,41,42]$, we investigated the influence of alcohol dependence on the stress-induced increases in $\mathrm{CeA}$ endocannabinoid levels in rats and evaluated the efficacy of endocannabinoid clearance inhibitors in ameliorating dependence-related increases in anxiety-like behavior and alcohol intake in both rat and mouse models because species specificity of the MAGL inhibitor has been reported [43].

The present data demonstrate that stress- and alcohol-induced increases in CeA 2-AG dialysate levels were blunted in rodents with a history of alcohol dependence. In fact, alcohol dependence was associated with a reduction in $\mathrm{CeA}$ 2-AG dialysate levels that declined further during acute abstinence and persisted into protracted abstinence. However, pharmacological restoration of alcohol dependence-associated deficits in 2-AG by selective inhibitors of degradative enzymes, especially MAGL, reversed both alcohol dependence-associated increases in anxiety-like behavior and excessive alcohol consumption.

Effects of chronic alcohol exposure and abstinence on endocannabinoids and amino acids in the $\mathrm{CeA}$

Chronic alcohol exposure decreased 2-AG dialysate levels. Substantial evidence indicates that chronic alcohol exposure alters endocannabinoid concentrations in the brain, but inconsistent findings among studies obscure definitive conclusions regarding the direction of change and regional nature of the effects [44]. Our data showed that prolonged alcohol exposure caused reductions of baseline 2-AG levels that persisted into protracted abstinence but did not alter AEA levels in the CeA. Interestingly, the deficiency of CeA 2-AG levels in dependent rats was enhanced during acute abstinence but this effect was counteracted by the re-exposure to alcohol and 2-AG levels returned to baseline dialysate levels. Therefore, although $A E A$ and 2-AG are both $C_{1}$ receptor agonists (AEA is a partial agonist, and 2-AG is a full agonist), their different profiles in alcohol dependence may reflect distinct pharmacological mechanisms and thus distinct physiological and behavioral effects $[45,46]$. In fact, these results suggest that 2-AG is mainly responsible for endocannabinoid neuroadaptations in the $\mathrm{CeA}$ in response to chronic alcohol treatment.

However, the enzymatic mechanism(s) involved in producing decreases in 2-AG signaling are presently unclear. Endogenous cannabinoid signaling in the brain is tightly regulated via enzymatic processes in vivo, suggesting that reduced levels of 2-AG in the CeA may be associated with DAGL downregulation and/or MAGL upregulation. In the present study, we found that rats exposed to chronic intermittent alcohol exhibited an overall increase in gene expression of several 2-AG metabolic enzymes. However, it is difficult to ascertain whether the alterations in mRNA expression are directly related to changes in protein levels or enzymatic activity, given that there are a multitude of posttranscriptional and translational mechanisms that would need to be considered. In the present study, we showed that there were higher mRNA levels of MAGL, although we also observed similar increases in $D A G L_{\alpha / \beta}$. Together, these findings are difficult to reconcile with regard to what may be driving the net reduction in 2-AG levels. Although we speculate that enhanced enzymatic degradation via MAGL corresponds with the pharmacological findings, we cannot dispute the possibility that these findings may also involve reduced activation of DAGL. In fact, previous research has shown that $\mathrm{DAGL}_{\alpha}$ knockout mice display reduced tissue concentrations of 2-AG in limbic regions [19]. Therefore, we are aware of this important limitation in our study and further investigation of functional alterations in DAGL and MAGL are warranted.

Chronic alcohol exposure increased GABA and glutamate dialysate levels. Because endocannabinoids are reported to suppress neurotransmitter release at both excitatory and inhibitory synapses with both short- and long-term effects [47-49], and dysregulations of GABA and glutamate signaling in the CeA are implicated in the development of alcohol dependence $[5,35,50]$, we examined GABA and glutamate levels in our study. The changes in both amino acid dialysate levels were opposite to the changes in 2-AG levels in the CeA. GABA and glutamate levels were significantly higher in alcohol-dependent rats than controls, and these interstitial levels were further increased during acute abstinence. Although we have not yet examined amino acid levels during protracted abstinence, our measures of 2-AG remained diminished in the $\mathrm{CeA}$ after 7 days. These findings are in agreement with previous studies reporting similar effects of alcohol dependence and abstinence on GABA and glutamate release in the $\mathrm{CeA}[35,50,51]$. While it is well established that 2-AG acts as a retrograde signal that inhibits the release of neurotransmitters via $C_{1}$ receptors $[31,52,53]$, the potential 
mechanistic association between 2-AG and amino acid levels in the CeA during alcohol exposure and abstinence remains an important question for future work.

Effects of restraint stress and chronic alcohol exposure on endocannabinoids in the $\mathrm{CeA}$

Restraint stress increased 2-AG dialysate levels. Previous studies showed that repeated exposure to restraint stress significantly increased tissue 2-AG levels in the forebrain and amygdala, and this endocannabinoid response attenuates stress-induced activation of the prefrontal cortex, hippocampus, and amygdala through a $C_{1}$ receptor-dependent process $[13,54,55]$. This led to the hypothesis that greater 2-AG formation counteracts stressinduced neuronal and behavioral activation and contributes to stress sensitivity and coping responses. The present study found transient stress-induced reductions of $A E A$ and prolonged elevations of 2-AG levels in the CeA, which is consistent with prior observations in post-mortem tissue [12, 13, 54-56]. Recent evidence demonstrates that acute stress rapidly increases $A E A$ hydrolysis by FAAH through a $\mathrm{CRF}_{1}$ receptor-mediated mechanism in the amygdala [57], as well as related work showing that similar mechanisms confer an anxiogenic phenotype in the CeA [58]. Collectively, these studies support the premise of dysregulated interaction between stress-promoting and constraining mechanisms in the amygdala that contribute to anxiety-like behaviors. The initial decline in brain AEA levels appears to enable the manifestation of stress responses, and subsequent increases in 2-AG appear to constrain and terminate stress responses, including anxiety-like behavior and HPA axis activation.

2-AG clearance inhibition attenuated anxiety-like behavior in alcohol-dependent animals. Based on this conceptualization, the loss of stress-induced elevations of CeA 2-AG levels in alcoholdependent rats may confer diminished capacity of the homeostatic regulation of stress responsivity, thus contributing to greater anxiety-like behavior in dependent animals. This hypothesis was tested by evaluating anxiety-like behavior in dependent animals and non-dependent animals following the inhibition of MAGL or FAAH. While both inhibitors ameliorated dependence-associated increases in anxiety-like behavior, we found greater effects using MAGL inhibitors. Regarding the effects of FAAH inhibitors, a recent work has demonstrated that the anxiety-like behavior associated with 2-AG deficiency is attenuated by inhibition of FAAH [59]. While an active role for AEA is not excluded, the partial reversal of FAAH inhibition on anxiety-like behavior could be associated with the fact that this degradative enzyme has the ability to hydrolyze 2-AG, although this endocannabinoid is not its preferential substrate [60]. Moreover, FAAH inhibitors did not produce their classical anxiolytic effects in non-dependent rodents but this discrepancy might be explained because our study was conducted under "non-stressed" conditions [41]. In fact, the anxiolytic-like effects in the alcohol group are consistent with evidence that alcohol dependence and protracted abstinence represent a state of "sustained stress" that may result from an increase in pro-stress signaling (e.g., CRF) and perhaps a reduction of the influence of anti-stress systems. Our results suggest that deficient 2-AG signaling may contribute to this state of "sustained stress," reflecting a breakdown of an inhibitory feedback mechanism that normally constrains or terminates stress responses.

Effects of alcohol self-administration and chronic alcohol exposure on endocannabinoids in the $\mathrm{CeA}$

Chronic alcohol exposure blunted alcohol intake-induced increase of 2-AG dialysate levels. Similar to restraint stress, we found that alcohol self-administration increased interstitial CeA 2-AG levels, with no concurrent change in AEA levels. The present data also showed that alcohol-induced increases in CeA 2-AG levels were blunted in dependent rats. Stress and alcohol intake activate the
HPA axis in the same manner to release cortisol/corticosterone from the adrenal gland, but chronic alcohol exposure results in significantly reduced baseline plasma corticosterone levels and blunted alcohol-induced increases in corticosterone [61]. Furthermore, the development of dependence-related compulsive and excessive alcohol consumption is correlated with reduced glucocorticoid receptor expression in several stress-responsive brain regions [36]. Strong evidence demonstrates the existence of an interaction between glucocorticoid and endocannabinoid signaling systems. Thus, electrophysiological findings show that the modulation of the synaptic transmission during acute stress in the basolateral amygdala is mediated by glucocorticoid-induced release of 2-AG at GABA synapses [62]. In addition, several studies have reported that corticosterone induces changes in the content of $A E A$ and 2-AG in opposite directions (AEA levels are decreased vs. 2-AG levels are increased) in different brain regions, including prefrontal cortex, amygdala, hippocampus, or hypothalamus [54, 63-65]. Because the increase in 2-AG levels is greater under chronic stress conditions, it is reasonable to think the possibility that diminished glucocorticoid signaling might contribute to diminished 2-AG tone in the $\mathrm{CeA}$, as well as the blunting of stress- and alcohol-induced recruitment of this lipid transmitter. However, further investigation is needed to determine the potential interaction between both systems in the context of alcohol dependence.

2-AG clearance inhibition attenuated excessive alcohol intake in alcohol-dependent animals. The present results suggest that alterations of endocannabinoid signaling in the $\mathrm{CeA}$ that result from alcohol dependence may contribute to excessive alcohol consumption. GABA and CRF are closely linked in the CeA. The greater activity of both systems may underlie some of the behavioral effects that were seen in alcohol animals, including excessive alcohol consumption $[66,67] . \mathrm{CB}_{1}$ and $\mathrm{CRF}_{1}$ receptors may compete for an influence on GABAergic transmission in the $\mathrm{CeA}$ (e.g., $\mathrm{CRF}_{1}$ activation increases $\mathrm{GABA}$ release [51], and $\mathrm{CB}_{1}$ activation decreases GABA release [31]). Thus, excessive alcohol consumption in dependent animals may result from lower $\mathrm{CB}_{1}$-mediated opposition to $\mathrm{CRF}_{1}$ stimulation induced of GABA release in the $\mathrm{CeA}$. Based on the results of microdialysis experiments for endocannabinoids, we suggest that this excessive alcohol consumption may be more strongly associated with deficient 2-AG than with AEA levels in the CeA. To test this hypothesis, we evaluated the effects of pharmacologically inhibiting MAGL and FAAH on alcohol intake in dependent and non-dependent animals. MAGL inhibition reduced alcohol intake selectively in alcohol-dependent rodents but FAAH inhibition did not consistently alter alcohol consumption in alcoholdependent rats or mice. In fact, a previous study with URB597 reported no effects of this potent and selective FAAH inhibitor on alcohol intake in both Wistar and Marchigian Sardinian alcoholpreferring (msP) rats [68]. Accordingly, the inconsistency in the effects of FAAH inhibition on alcohol intake, but also on anxietylike behaviors in alcohol-dependent rodents, requires more investigation.

In summary, lower basal and stimulated CeA 2-AG dialysate levels were observed in alcohol-dependent animals. The "restoration" of 2-AG signaling with the inhibition of 2-AG clearance, especially via MAGL, ameliorated abstinence-related behavioral pathologies (e.g., anxiety and excessive alcohol intake). These findings strongly implicate deficient 2-AG signaling in alcohol dependence-related behaviors.

\section{ACKNOWLEDGEMENTS}

We thank Dr. George F. Koob for insightful comments on the manuscript and Mr. Michael Arends for editing the manuscript. We dedicate this manuscript in loving memory to our departed friend, colleague, and mentor, LHP. He was an extraordinary researcher in the field of endocannabinoid signaling, stress, and drug addiction. 


\section{FUNDING AND DISCLOSURE}

This research was supported by the following grants: National Institute on Alcohol Abuse and Alcoholism (AA020404, AA022249, and AA024146 to RMF; AA006420 to RMF and MR; AA017447 and AA015566 to MR; and K99-AA025393 to LAN) and National Institutes of Health (K99/R00DA037344 to JS). This research was also supported by the Pearson Center for Alcoholism and Addiction Research, Instituto de Salud Carlos III (ISCIII) and European Regional Development Funds-European Union (ERDF-EU; Subprograma RETICS Red de Trastornos Adictivos RD12/0028/0001), Ministerio de Economía y Competitividad and ISCIII (PI16/01953 and PI17/02026), Ministerio de Sanidad, Servicios Sociales e lgualdad and Plan Nacional sobre Drogas (PND2017/043), and Consejería de Economía, Innovación y Ciencia, Junta de Andalucía, and ERDF-EU (CTS-433). AS and FJP hold a "Miguel Servet" research contract funded by ISCIII and ERDF-EU (CP14/00173 and CP14/00212, respectively). This is article number 29530 from The Scripps Research Institute.

\section{ADDITIONAL INFORMATION}

Supplementary information accompanies this paper at (https://doi.org/10.1038/ s41386-018-0055-3)

Conflict of interest: The authors declare that they have no conflict of interest.

Publisher's note: Springer Nature remains neutral with regard to jurisdictional claims in published maps and institutional affiliations.

\section{REFERENCES}

1. Koob GF. Theoretical frameworks and mechanistic aspects of alcohol addiction: alcohol addiction as a reward deficit disorder. Curr Top Behav Neurosci. 2013;13:3-30

2. Heilig M, Koob GF, Ekman R, Britton KT. Corticotropin-releasing factor and neuropeptide Y: role in emotional integration. Trends Neurosci. 1994;17:80-85.

3. Lindell SG, Schwandt ML, Sun H, Sparenborg JD, Bjork K, Kasckow JW, et al. Functional NPY variation as a factor in stress resilience and alcohol consumption in rhesus macaques. Arch Gen Psychiatry. 2010;67:423-31.

4. Caberlotto L, Rimondini R, Hansson A, Eriksson S, Heilig M. Corticotropin-releasing hormone $(\mathrm{CRH})$ mRNA expression in rat central amygdala in cannabinoid tolerance and withdrawal: evidence for an allostatic shift? Neuropsychopharmacology. 2004;29:15-22.

5. Gilpin NW, Roberto M. Neuropeptide modulation of central amygdala neuroplasticity is a key mediator of alcohol dependence. Neurosci Biobehav Rev. 2012;36:873-88.

6. Koob GF, Volkow ND. Neurocircuitry of addiction. Neuropsychopharmacology. 2010;35:217-38.

7. Witkin JM, Statnick MA, Rorick-Kehn LM, Pintar JE, Ansonoff M, Chen Y, et al. The biology of nociceptin/orphanin FQ (N/OFQ) related to obesity, stress, anxiety, mood, and drug dependence. Pharmacol Ther. 2014;141:283-99.

8. Ciccocioppo R, Cippitelli A, Economidou D, Fedeli A, Massi M. Nociceptin/ orphanin FQ acts as a functional antagonist of corticotropin-releasing factor to inhibit its anorectic effect. Physiol Behav. 2004;82:63-68.

9. Ciccocioppo R, de Guglielmo G, Hansson AC, Ubaldi M, Kallupi M, Cruz MT, et al. Restraint stress alters nociceptin/orphanin FQ and CRF systems in the rat central amygdala: significance for anxiety-like behaviors. J Neurosci. 2014;34:363-72.

10. Morena M, Patel S, Bains JS, Hill MN. Neurobiological interactions between stress and the endocannabinoid system. Neuropsychopharmacology. 2016;41:80-102.

11. Dlugos A, Childs E, Stuhr KL, Hillard CJ, de Wit H. Acute stress increases circulating anandamide and other $\mathrm{N}$-acylethanolamines in healthy humans. Neuropsychopharmacology. 2012;37:2416-27.

12. Hill MN, McLaughlin RJ, Morrish AC, Viau V, Floresco SB, Hillard CJ, et al. Suppression of amygdalar endocannabinoid signaling by stress contributes to activation of the hypothalamic-pituitary-adrenal axis. Neuropsychopharmacology. 2009;34:2733-45.

13. Patel S, Kingsley PJ, Mackie K, Marnett LJ, Winder DG. Repeated homotypic stress elevates 2-arachidonoylglycerol levels and enhances short-term endocannabinoid signaling at inhibitory synapses in basolateral amygdala. Neuropsychopharmacology. 2009;34:2699-709.

14. Bluett RJ, Gamble-George JC, Hermanson DJ, Hartley ND, Marnett LJ, Patel S Central anandamide deficiency predicts stress-induced anxiety: behavioral reversal through endocannabinoid augmentation. Transl Psychiatry. 2014;4: e408.

15. Patel S, Roelke CT, Rademacher DJ, Cullinan WE, Hillard CJ. Endocannabinoid signaling negatively modulates stress-induced activation of the hypothalamicpituitary-adrenal axis. Endocrinology. 2004;145:5431-8.
16. Sumislawski JJ, Ramikie TS, Patel S. Reversible gating of endocannabinoid plasticity in the amygdala by chronic stress: a potential role for monoacylglycerol lipase inhibition in the prevention of stress-induced behavioral adaptation. Neuropsychopharmacology. 2011;36:2750-61.

17. Haller J, Varga B, Ledent C, Freund TF. CB1 cannabinoid receptors mediate anxiolytic effects: convergent genetic and pharmacological evidence with CB1specific agents. Behav Pharmacol. 2004;15:299-304.

18. Bellocchio L, Soria-Gomez E, Quarta C, Metna-Laurent M, Cardinal P, Binder E, et al. Activation of the sympathetic nervous system mediates hypophagic and anxiety-like effects of $\mathrm{CB}(1)$ receptor blockade. Proc Natl Acad Sci USA. 2013;110:4786-91.

19. Shonesy BC, Bluett RJ, Ramikie TS, Baldi R, Hermanson DJ, Kingsley PJ, et al. Genetic disruption of 2-arachidonoylglycerol synthesis reveals a key role for endocannabinoid signaling in anxiety modulation. Cell Rep. 2014;9:1644-53.

20. Dincheva I, Drysdale AT, Hartley CA, Johnson DC, Jing D, King EC, et al. FAAH genetic variation enhances fronto-amygdala function in mouse and human. Nat Commun. 2015;6:6395.

21. Hill MN, Miller GE, Ho WS, Gorzalka BB, Hillard CJ. Serum endocannabinoid content is altered in females with depressive disorders: a preliminary report. Pharmacopsychiatry. 2008;41:48-53.

22. Chouker A, Kaufmann I, Kreth S, Hauer D, Feuerecker M, Thieme D, et al. Motion sickness, stress and the endocannabinoid system. PLoS ONE. 2010;5:e10752.

23. Hill MN, Patel S. Translational evidence for the involvement of the endocannabinoid system in stress-related psychiatric illnesses. Biol Mood Anxiety Disord. 2013b;3:19.

24. Hillard CJ, Weinlander KM, Stuhr KL. Contributions of endocannabinoid signaling to psychiatric disorders in humans: genetic and biochemical evidence. Neuroscience. 2012;204:207-29.

25. Henricks AM, Berger AL, Lugo JM, Baxter-Potter LN, Bieniasz KV, Craft RM, et al. Sex differences in alcohol consumption and alterations in nucleus accumbens endocannabinoid mRNA in alcohol-dependent rats. Neuroscience. 2016;335: 195-206.

26. Henricks AM, Berger AL, Lugo JM, Baxter-Potter LN, Bieniasz KV, Petrie G, et al. Sex- and hormone-dependent alterations in alcohol withdrawal-induced anxiety and corticolimbic endocannabinoid signaling. Neuropharmacology. 2017;124:121-33

27. Serrano A, Rivera P, Pavon FJ, Decara J, Suarez J, Rodriguez de Fonseca F, et al Differential effects of single versus repeated alcohol withdrawal on the expression of endocannabinoid system-related genes in the rat amygdala. Alcohol Clin Exp Res. 2012;36:984-94.

28. Vinod KY, Kassir SA, Hungund BL, Cooper TB, Mann JJ, Arango V. Selective alterations of the $\mathrm{CB} 1$ receptors and the fatty acid amide hydrolase in the ventral striatum of alcoholics and suicides. J Psychiatr Res. 2010;44:591-7.

29. Hirvonen J, Zanotti-Fregonara P, Umhau JC, George DT, Rallis-Frutos D, Lyoo $\mathrm{CH}$, et al. Reduced cannabinoid CB1 receptor binding in alcohol dependence measured with positron emission tomography. Mol Psychiatry. 2013;18:916-21.

30. Ceccarini J, Hompes T, Verhaeghen A, Casteels C, Peuskens H, Bormans G, et al. Changes in cerebral $\mathrm{CB} 1$ receptor availability after acute and chronic alcohol abuse and monitored abstinence. J Neurosci. 2014;34:2822-31.

31. Varodayan FP, Soni N, Bajo M, Luu G, Madamba SG, Schweitzer P, et al. Chronic ethanol exposure decreases $\mathrm{CB} 1$ receptor function at GABAergic synapses in the rat central amygdala. Addict Biol. 2016;21:788-801.

32. Ahn K, Johnson DS, Mileni M, Beidler D, Long JZ, McKinney MK, et al. Discovery and characterization of a highly selective FAAH inhibitor that reduces inflammatory pain. Chem Biol. 2009;16:411-20.

33. Long JZ, Li W, Booker L, Burston JJ, Kinsey SG, Schlosburg JE, et al. Selective blockade of 2-arachidonoylglycerol hydrolysis produces cannabinoid behavioral effects. Nat Chem Biol. 2009;5:37-44.

34. Niphakis MJ, Cognetta AB 3rd, Chang JW, Buczynski MW, Parsons LH, Byrne F, et al. Evaluation of NHS carbamates as a potent and selective class of endocannabinoid hydrolase inhibitors. ACS Chem Neurosci. 2013;4:1322-32.

35. Roberto M, Madamba SG, Stouffer DG, Parsons LH, Siggins GR. Increased GABA release in the central amygdala of ethanol-dependent rats. J Neurosci. 2004a;24:10159-66.

36. Vendruscolo LF, Barbier E, Schlosburg JE, Misra KK, Whitfield TW Jr., Logrip ML, et al. Corticosteroid-dependent plasticity mediates compulsive alcohol drinking in rats. J Neurosci. 2012;32:7563-71.

37. Merlo Pich E, Lorang M, Yeganeh M, Rodriguez de Fonseca F, Raber J, Koob GF, et al. Increase of extracellular corticotropin-releasing factor-like immunoreactivity levels in the amygdala of awake rats during restraint stress and ethanol withdrawal as measured by microdialysis. J Neurosci. 1995;15:5439-47.

38. Paxinos G, Watson C. The Rat Brain in Stereotaxic Coordinates. New York: Academic Press, Spiral Bound; 1998 
39. Caille S, Alvarez-Jaimes L, Polis I, Stouffer DG, Parsons LH. Specific alterations of extracellular endocannabinoid levels in the nucleus accumbens by ethanol, heroin, and cocaine self-administration. J Neurosci. 2007; 27:3695-702.

40. Zapata A, Chefer VI, Shippenberg TS, Denoroy L. Detection and quantification of neurotransmitters in dialysates. Curr Protoc Neurosci. 2009:4:1-30.

41. Haller J, Barna I, Barsvari B, Gyimesi Pelczer K, Yasar S, Panlilio LV, et al. Interactions between environmental aversiveness and the anxiolytic effects of enhanced cannabinoid signaling by FAAH inhibition in rats. Psychopharmacol (Berl). 2009;204:607-16.

42. Sciolino NR, Zhou W, Hohmann AG. Enhancement of endocannabinoid signaling with JZL184, an inhibitor of the 2-arachidonoylglycerol hydrolyzing enzyme monoacylglycerol lipase, produces anxiolytic effects under conditions of high environmental aversiveness in rats. Pharmacol Res. 2011;64:226-34.

43. Wiskerke J, Irimia C, Cravatt BF, De Vries TJ, Schoffelmeer AN, Pattij T, et al. Characterization of the effects of reuptake and hydrolysis inhibition on interstitial endocannabinoid levels in the brain: an in vivo microdialysis study. ACS Chem Neurosci. 2012;3:407-17.

44. Serrano A, Parsons LH. Endocannabinoid influence in drug reinforcement, dependence and addiction-related behaviors. Pharmacol Ther. 2011;132:215-41.

45. Hillard CJ. Biochemistry and pharmacology of the endocannabinoids arachidonylethanolamide and 2-arachidonylglycerol. Prostaglandins Other Lipid Mediat. 2000;61:3-18.

46. Sugiura T, Kobayashi Y, Oka S, Waku K. Biosynthesis and degradation of anandamide and 2-arachidonoylglycerol and their possible physiological significance. Prostaglandins Leukot Essent Fat Acids. 2002;66:173-92.

47. Kano M, Ohno-Shosaku T, Hashimotodani $Y$, Uchigashima M, Watanabe $M$. Endocannabinoid-mediated control of synaptic transmission. Physiol Rev. 2009;89:309-80.

48. Lovinger DM. Presynaptic modulation by endocannabinoids. Handb Exp Pharmacol. 2008;184:435-77.

49. Marsicano G, Lutz B. Neuromodulatory functions of the endocannabinoid system. J Endocrinol Invest. 2006;29:27-46

50. Roberto M, Schweitzer P, Madamba SG, Stouffer DG, Parsons LH, Siggins GR. Acute and chronic ethanol alter glutamatergic transmission in rat central amygdala: an in vitro and in vivo analysis. J Neurosci. 2004;24:1594-603.

51. Roberto M, Cruz MT, Gilpin NW, Sabino V, Schweitzer P, Bajo M, et al. Corticotropin releasing factor-induced amygdala gamma-aminobutyric Acid release plays a key role in alcohol dependence. Biol Psychiatry. 2010;67:831-9.

52. Gerdeman G, Lovinger DM. CB1 cannabinoid receptor inhibits synaptic release of glutamate in rat dorsolateral striatum. J Neurophysiol. 2001;85:468-71.

53. Roberto $M$, Cruz M, Bajo M, Siggins GR, Parsons LH, Schweitzer P. The endocannabinoid system tonically regulates inhibitory transmission and depresses the effect of ethanol in central amygdala. Neuropsychopharmacology. 2010;35:1962-72.
54. Hill MN, McLaughlin RJ, Bingham B, Shrestha L, Lee T, Gray JM, et al. Endogenous cannabinoid signaling is essential for stress adaptation. Proc Natl Acad Sci USA. 2010;107:9406-11.

55. Patel S, Roelke CT, Rademacher DJ, Hillard CJ. Inhibition of restraint stressinduced neural and behavioural activation by endogenous cannabinoid signalling. Eur J Neurosci. 2005;21:1057-69.

56. Hill MN, Kumar SA, Filipski SB, Iverson M, Stuhr KL, Keith JM, et al. Disruption of fatty acid amide hydrolase activity prevents the effects of chronic stress on anxiety and amygdalar microstructure. Mol Psychiatry. 2013;18:1125-35.

57. Gray JM, Vecchiarelli HA, Morena M, Lee TT, Hermanson DJ, Kim AB, et al. Corticotropin-releasing hormone drives anandamide hydrolysis in the amygdala to promote anxiety. J Neurosci. 2015;35:3879-92.

58. Natividad LA, Buczynski MW, Herman MA, Kirson D, Oleata CS, Irimia C, et al. Constitutive increases in amygdalar corticotropin-releasing factor and fatty acid amide hydrolase drive an anxious phenotype. Biol Psychiatry. 2017;82:500-510.

59. Bedse G, Hartley ND, Neale E, Gaulden AD, Patrick TA, Kingsley PJ, et al. Functional redundancy between canonical endocannabinoid signaling systems in the modulation of anxiety. Biol Psychiatry. 2017;82:488-99.

60. Di Marzo V, De Petrocellis L. Why do cannabinoid receptors have more than one endogenous ligand? Philos Trans R Soc Lond B Biol Sci. 2012;367:3216-28.

61. Richardson HN, Lee SY, O'Dell LE, Koob GF, Rivier CL. Alcohol self-administration acutely stimulates the hypothalamic-pituitary-adrenal axis, but alcohol dependence leads to a dampened neuroendocrine state. Eur J Neurosci. 2008;28:1641-53.

62. Di S, Itoga CA, Fisher MO, Solomonow J, Roltsch EA, Gilpin NW, et al. Acute stress suppresses synaptic inhibition and increases anxiety via endocannabinoid release in the basolateral amygdala. J Neurosci. 2016;36:8461-70.

63. Evanson NK, Tasker JG, Hill MN, Hillard CJ, Herman JP. Fast feedback inhibition of the HPA axis by glucocorticoids is mediated by endocannabinoid signaling. Endocrinology. 2010;151:4811-9.

64. Hill MN, McLaughlin RJ, Pan B, Fitzgerald ML, Roberts CJ, Lee $\Pi$, et al. Recruitment of prefrontal cortical endocannabinoid signaling by glucocorticoids contributes to termination of the stress response. J Neurosci. 2011;31:10506-15.

65. Wang M, Hill MN, Zhang L, Gorzalka BB, Hillard CJ, Alger BE. Acute restraint stress enhances hippocampal endocannabinoid function via glucocorticoid receptor activation. J Psychopharmacol. 2012;26:56-70.

66. Valdez GR, Sabino V, Koob GF. Increased anxiety-like behavior and ethanol selfadministration in dependent rats: reversal via corticotropin-releasing factor-2 receptor activation. Alcohol Clin Exp Res. 2004;28:865-72.

67. Valdez GR, Zorrilla EP, Roberts AJ, Koob GF. Antagonism of corticotropin-releasing factor attenuates the enhanced responsiveness to stress observed during protracted ethanol abstinence. Alcohol. 2003;29:55-60.

68. Cippitelli A, Cannella N, Braconi S, Duranti A, Tontini A, Bilbao A, et al. Increase of brain endocannabinoid anandamide levels by FAAH inhibition and alcohol abuse behaviours in the rat. Psychopharmacol (Berl). 2008;198:449-60. 